Volume 2

Issue 3 - Vascular Disease

Article 5

8-14-2015

\title{
Subclavian Vein Stenosis/Occlusion Following Transvenous \\ Cardiac Pacemaker and Defibrillator Implantation: Incidence, Pathophysiology and Current Management
}

Brian O'Leary

Suhail Allaqaband

Follow this and additional works at: https://aah.org/jpcrr

Part of the Cardiology Commons, Cardiovascular Diseases Commons, Cardiovascular System Commons, and the Medical Biotechnology Commons

\section{Recommended Citation}

O'Leary B, Allaqaband S. Subclavian Vein Stenosis/Occlusion Following Transvenous Cardiac Pacemaker and Defibrillator Implantation: Incidence, Pathophysiology and Current Management. J Patient Cent Res Rev 2015;2:112-117. http://dx.doi.org/10.17294/2330-0698.1074

Published quarterly by Midwest-based health system Advocate Aurora Health and indexed in PubMed Central, the Journal of Patient-Centered Research and Reviews (JPCRR) is an open access, peer-reviewed medical journal focused on disseminating scholarly works devoted to improving patient-centered care practices, health outcomes, and the patient experience. 


\title{
Subclavian Vein Stenosis/Occlusion Following Transvenous Cardiac Pacemaker and Defibrillator Implantation: Incidence, Pathophysiology and Current Management
}

\author{
Brian O'Leary, MD, Suhail Allaqaband, MD \\ Aurora Cardiovascular Services, Aurora Sinai/Aurora St. Luke's Medical Centers, University of Wisconsin \\ School of Medicine and Public Health, Milwaukee, WI
}

\begin{abstract}
Subclavian vein stenosis is a common, but usually asymptomatic, complication following cardiac device placement. In addition to reviewing the literature on incidence, pathogenesis and management options for this important clinical problem, we describe two cases of symptomatic subclavian vein occlusion following pacemaker/defibrillator placement and successful treatment with venoplasty and stenting.
\end{abstract}

Keywords subclavian vein, stenosis, pacemaker, complication, venoplasty

The number of pacemakers and defibrillators implanted in the United States and worldwide continues to increase. In 2009 alone, there were more than 1 million pacemaker insertions or replacements and more than 300,000 defibrillator implants. These numbers continue to grow along with an aging population and expanding indications for device therapy. ${ }^{1}$ Subclavian vein stenosis/occlusion following transvenous cardiac device placement is a known complication of the procedure. ${ }^{2,3}$ It is an important clinical problem to recognize, especially with the increasing numbers of pacemaker and defibrillator implantations. Subclavian vein stenosis can lead to symptoms such as ipsilateral arm edema, parasthesia and pain in a minority of patients. Acute thrombosis related to the cardiac device is rare but most often symptomatic. Chronic thrombosis/stenosis is more common but usually asymptomatic.

Subclavian vein stenosis related to an intracardiac device, even when asymptomatic, can lead to problems with lead revision or device exchange., ${ }^{2,3}$ Variable incidence has been reported in the literature, but up to $50 \%$ of patients may develop at least moderate subclavian vein stenosis, defined in most studies as a greater than $50 \%$ luminal narrowing by contrast venography. Even with more severe luminal narrowing

Correspondence: Suhail Allaqaband, MD, 2801 W. Kinnickinnic River Parkway, Suite 840, Milwaukee, WI, 53215,

T: 414-649-3909, F: 414-649-3551, Email:

publishing3@aurora.org (greater than $70 \%$ ), most patients remain asymptomatic due to venous collateral formation. ${ }^{4-8}$ Risk factors for subclavian vein stenosis have not been well elucidated. Various management strategies have been employed, including anticoagulation, lead extraction, percutaneous venoplasty with or without stenting, and surgical bypass. However, no consensus regarding the optimal treatment of this problem exists, and there is limited evidence to support one approach over another.

Herein we review the literature in an effort to further understand what questions have been answered and areas where further study is important for the management of this unique vascular complication. Also provided are descriptions of two cases of symptomatic subclavian vein occlusion associated with transvenous pacemaker and defibrillator leads that were treated at our institution with successful percutaneous venoplasty and stenting.

\section{Illustrative Case \#1 (Figure 1)}

A 67-year-old man with a history of idiopathic dilated cardiomyopathy and paroxysmal atrial fibrillation on rivaroxaban anticoagulation (with documented compliance) underwent placement of a left-sided biventricular implantable cardioverter defibrillator (Viva XT, Medtronic Inc., Minneapolis, MN) one year prior to presentation. There was no prior history of clotting disorders or venous thromboembolism. The procedure and immediate postoperative course were without complications. 


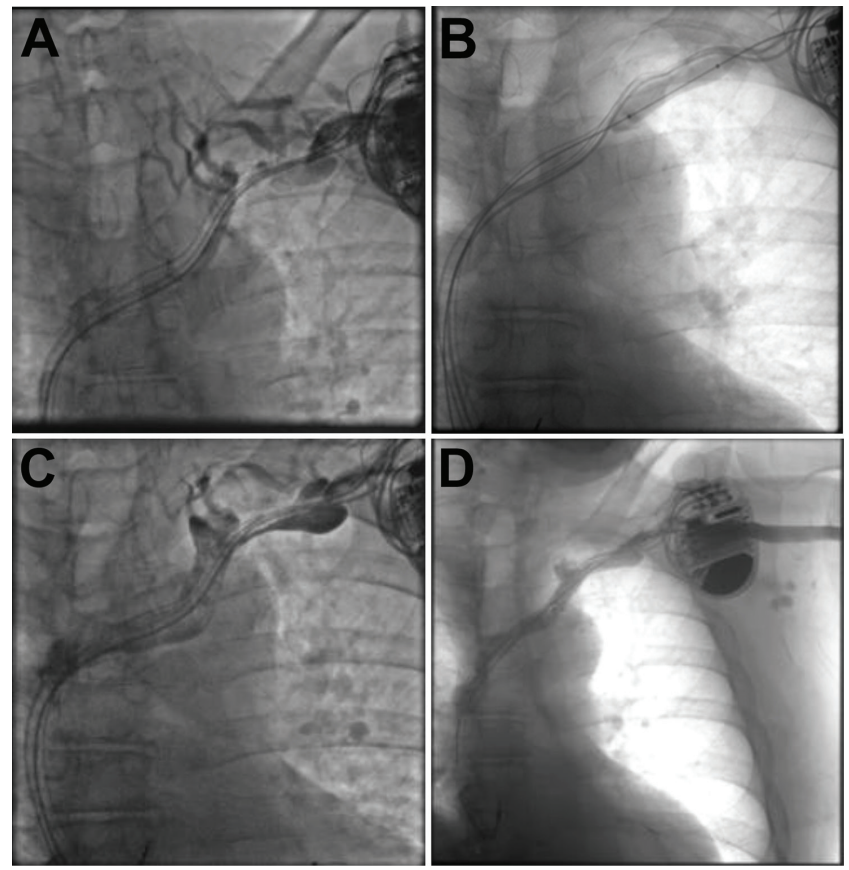

Figure 1. A: Subclavian venography demonstrating total occlusion in the presence of a biventricular implantable cardioverter-defibrillator with collateral formation.

B: Balloon venoplasty was performed. C: Significant recoil can be seen on postvenoplasty angiography. $\boldsymbol{D}$ : After stenting the lesion, only minimal residual stenosis is evident.

One month prior to presentation, the patient saw his primary care physician with a complaint of isolated, painful left arm and hand swelling. The patient also noticed visible venous collaterals over the left shoulder and pectoral area. Upper extremity venous ultrasound raised concern for significant left subclavian vein stenosis or occlusion but was limited in its evaluation due to the presence of existing pacemaker leads and the left clavicle. The patient was advised to undergo further evaluation with a venogram.

Left subclavian venography accessed via the left brachial vein demonstrated a total occlusion of the left subclavian vein near the site of entry of the pacemaker wires. There was difficulty in crossing the lesion from the arm with multiple catheters and wires. Femoral venous access was obtained and an attempt was made to cross from a retrograde approach. Ultimately, using retrograde injections, a support catheter (QuickCross $^{\circledR}$, Spectranetics Corp., Colorado Springs, CO) and stiff glidewire were used to successfully cross the lesion from an antegrade approach. The lesion

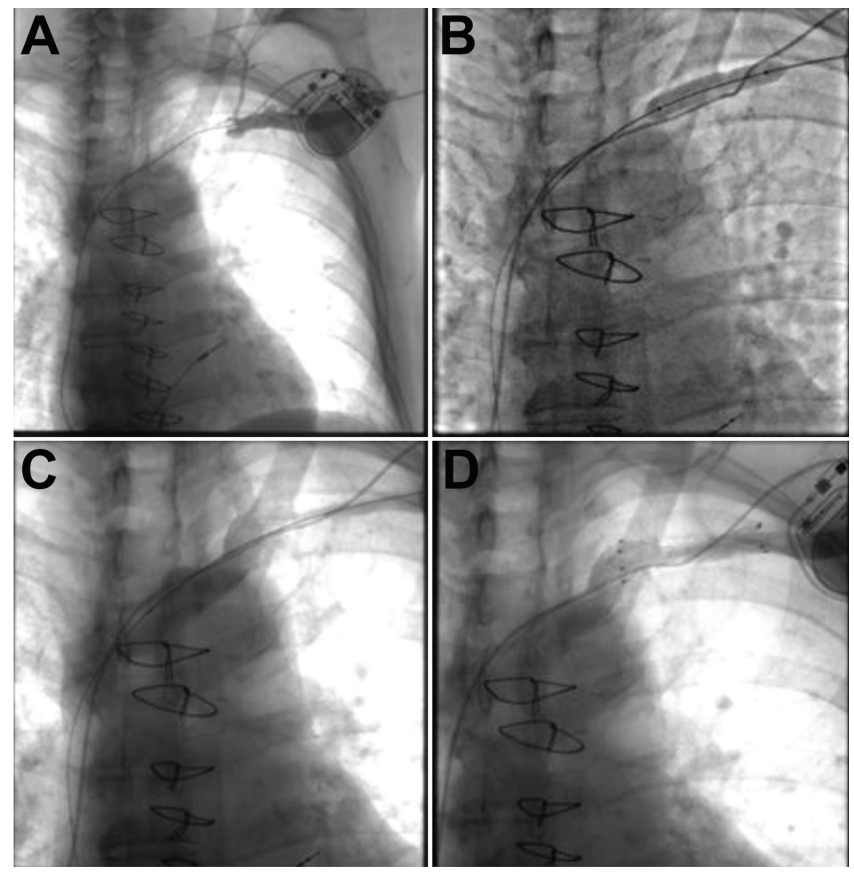

Figure 2. A: Subclavian venography demonstrating total occlusion in the presence of a single-chamber pacemaker. B: Balloon venoplasty. C: Significant recoil is shown on postvenoplasty angiography. D: After stenting the lesion, only minimal residual stenosis is evident.

was dilated at the lead insertion site with $5 \times 40-\mathrm{mm}$ and $10 \times 40$-mm balloons, and brisk antegrade flow was restored. However, with the removal of the wire, repeat angiography demonstrated reocclusion due to recoil at the lesion site. After consultation with the patient's electrophysiologist, a decision was made to proceed with stenting with the full understanding that the implanted pacemaker leads would be trapped behind the stent. A $12 \times 60$-mm stent (LifeStar ${ }^{\circledR}$, Bard Peripheral Vascular Inc., Tempe, AZ) was deployed and postdilated using a $10-\mathrm{mm}$ balloon, with an excellent angiographic result.

\section{Illustrative Case \#2 (Figure 2)}

A 79-year-old man with a history of hypertension, postsurgical revascularization coronary artery disease and persistent atrial fibrillation on warfarin anticoagulation underwent implantation of a single-chamber pacemaker (Accent $^{\mathrm{TM}}$, St. Jude Medical Inc., St. Paul, MN) one year prior to presentation for tachycardia-bradycardia syndrome. There was no history of previous venous thromboembolism or clotting disorder, and the patient 
was compliant with anticoagulation. The procedure and immediate postprocedure course were uncomplicated.

Ten months following pacemaker implantation, the patient saw his primary care physician for isolated left arm and hand swelling and development of dilated venous collaterals over the left chest area. A duplex ultrasound was ordered at that time and demonstrated slow flow in the left subclavian vein, raising suspicion of stenosis or occlusion of the subclavian vein. A venogram was recommended.

Left subclavian venography accessed via the left brachial vein demonstrated a total occlusion of the left subclavian vein near the entry site of the pacemaker lead. Using an angled glidewire, we were able to cross the occlusion. Venoplasty was then performed with an $8 \times 40$-mm balloon with multiple inflations up to 10 atmospheres. An $8 \times 40$-mm noncompliant balloon was then used up to 14 atmospheres, given significant recoil at the lesion site after initial venoplasty. Because of unsatisfactory flow across the lesion, a $12 \times 40$ mm stent (LifeStent ${ }^{\circledR}$, Bard Peripheral Vascular) was deployed and postdilated with an 8-mm noncompliant balloon, with an excellent angiographic result.

At 1-month follow-up, both patients had complete resolution of the arm swelling, and the subcutaneous venous collaterals had completely disappeared.

\section{Pathophysiology}

Venous thrombosis and stenosis were reported in the literature shortly after the first transvenous pacemakers were implanted. Early and late venous thrombosis has been described.,5 Late thrombosis is often asymptomatic, the result of chronic fibrosis around the device leads that enables collaterals to form. Acute venous thrombosis is less common and often symptomatic. Most of the modern histopathologic data has focused on the complex inflammatory and fibrotic changes that occur at the endocardial lead interface. Autopsy studies have identified similar inflammatory and fibrotic changes at the insertion site of the device leads in the vein. ${ }^{9,10}$ Dense fibrotic adhesions are routinely encountered when lead removal is necessary and have formed the basis for the development of excimer laser lead extraction. ${ }^{11}$ This fibrosis can occur more frequently at characteristic anatomic sites like the lead insertion point, venous bifurcation sites and the costoclavicular space. It is not well characterized why particular anatomic sites are more prone to stenosis, but the cause is likely multifactorial and related to endothelial injury from insertion as well as repetitive mechanical trauma at bifurcation sites or where bony compression may occur. Two studies have suggested that temporary pacemaker insertion prior to permanent implant and prior pacemaker insertion before defibrillator placement were risk factors associated with stenosis, presumably due to repetitive vessel trauma. ${ }^{7,12}$

\section{Epidemiology}

The incidence of subclavian vein stenosis after device implantation varies widely in the literature, ranging from $30 \%$ to $50 \% .4-8,{ }^{12,13}$ Some of this variation depends on the modality used to diagnose the problem, i.e. ultrasound versus contrast venography. Other reasons for the variation are likely diverse study populations that vary considerably in size, both retrospective and prospective data acquisition and nonstandard definitions of significant stenosis.

Multiple studies in which routine postimplant venography was performed have demonstrated significant stenosis rates. Many studies have defined the degree of stenosis as mild $(<50 \%)$, moderate $(50-70 \%)$ and severe $(>70 \%)$. Antonelli et al. ${ }^{5}$ performed consecutive venography on 40 patients and found significant venous stenosis in $23 \%$ at a mean postprocedure follow-up of 4 months. Studies with longer follow-up have reported rates as high as $50 \%$. Da Costa and colleagues ${ }^{7}$ prospectively studied venography at 6 months postimplant in 202 patients. Greater than moderate stenosis was identified in 51\% of patients. Most of the patients in these studies were asymptomatic, thought to be secondary to collateral venous circulation that develops as the stenosis gradually worsens. The incidence of symptomatic subclavian vein stenosis in patients with cardiac devices is estimated at $1-5 \%$. However, this may be an underreported clinical problem.

Risk factors for the development of subclavian vein stenosis have been described but are not well characterized. In Da Costa et al.'s study of both symptomatic and asymptomatic patients, low ejection fraction and a prior temporary pacemaker conveyed 
increased risk. There are conflicting data on whether the number of leads present conveys greater risk. Other studies have investigated but found no link in a variety of patient- and device-specific factors. These include age, sex, pacemaker or defibrillator device, time from lead implant, lead type or material (silicone or polyurethane) and entry site, among others..$^{7,13}$

\section{Clinical Characteristics and Diagnosis}

Symptomatic patients with chronic lead-related subclavian vein stenosis/occlusion often present more than one month after device implantation with painful arm swelling that may be associated with cyanosis and visible venous collaterals over the ipsilateral chest and upper extremity. Rarely, pulmonary embolism can be a presenting symptom as reported in Da Costa et al.'s prospective study. ${ }^{7}$ The majority of patients remain asymptomatic due to venous collateral formation. Symptoms may develop due to inadequate collaterals or their acute obstruction, an acute thrombotic event on an existing moderate venous stenosis in which collaterals have not formed, or the presence of an ipsilateral arteriovenous fistula in dialysis patients. ${ }^{14}$

Diagnosis may be apparent based on history and physical exam alone. Often, a venous duplex ultrasound will identify a high-grade stenosis or occlusion. ${ }^{15}$ Computed tomography is an additional noninvasive option when ultrasound is unavailable or inadequate. ${ }^{16}$ Definitive diagnosis is made with contrast venography. ${ }^{2,12}$

\section{Management}

The optimal management strategy for the treatment of patients with subclavian vein stenosis related to a transvenous lead has not been systematically studied. Most of the literature has focused on management options for asymptomatic patients with venous stenosis who need an additional lead or lead revision and in whom the diagnosis is made incidentally. ${ }^{17-22}$ Options for management of these patients include contralateral access, lead extraction with reimplantation or epicardial lead placement. Surgical approaches for bypass or reconstruction exist but are rarely used in the modern era. ${ }^{23}$ An alternative option, percutaneous venoplasty, is being increasingly utilized as a safe and effective method to preserve ipsilateral access even in the setting of chronic occlusion. Worley and colleagues $^{24}$ reported successful venoplasty in 371 of 373 consecutive patients (over an 11-year period) who were found to have significant subclavian stenosis while undergoing lead revision or upgrade.

The optimal management strategy of the symptomatic patient with subclavian stenosis in which the existing lead is functioning normally is not known. Spittell et al. ${ }^{25}$ reported early success with balloon venoplasty in the treatment of two patients with symptomatic venous stenosis. Conservative options include watchful waiting for collateral vessels to develop. Anticoagulation and thrombolytic therapy also have been utilized, but they are unlikely to be effective for the chronic fibrotic lesions that often exist in these patients. ${ }^{23}$ For the persistent symptomatic patient, device extraction can be considered, but this comes with an approximately $1-2 \%$ risk of significant morbidity and mortality, including tamponade, valve injury and hemothorax. ${ }^{11}$ Venoplasty with or without stenting is an alternative approach that enables the device and leads to stay in place, avoiding the risks of lead extraction as well as preserving ipsilateral access. In Worley et al.'s large, retrospective, single-center review, no procedural complications were noted in 373 venoplasty procedures. ${ }^{24}$

Many reports in the literature describe the successful treatment of symptomatic patients with superior vena cava stenosis due to transvenous leads. ${ }^{26-30}$ Riley et al. ${ }^{23}$ performed a pooled analysis of 104 patients treated for lead-associated superior vena cava syndrome over a period of 39 years. The treatment options included anticoagulation ( $\mathrm{n}=29$ patients), thrombolysis $(\mathrm{n}=11)$, venoplasty $(\mathrm{n}=16)$, surgery $(\mathrm{n}=23)$ and stenting $(n=25)$. Stenting was the superior modality, with $5 \%$ recurrence over a median of 9.5 months. Surgery had a $12 \%$ recurrence rate, venoplasty $23 \%$, anticoagulation $21 \%$ and thrombolysis $33 \%$. Complication rates were not reported.

Kalman et al. ${ }^{31}$ reported their single-center experience with a small heterogeneous group of patients with symptomatic venous stenosis treated with a variety of interventional techniques, including directed thrombolysis, venoplasty and stenting as a bailout option. Of the patients in their cohort, $15 \%$ had a pacemaker lead and $15 \%$ received a stent. They reported a 70\% 2-year patency rate for the 
entire group, with no complications noted from the stenting technique. The low rate of stent use is in line with the Heart Rhythm Society expert consensus recommendation to avoid stenting in patients with symptomatic pacemaker-related subclavian stenosis. ${ }^{32}$ There is concern that stenting can damage device leads and lead to pacemaker malfunction, but this has been reported rarely in the literature. ${ }^{33}$

\section{Conclusions}

Cardiac device-related subclavian vein stenosis is a common problem that most often remains clinically silent. The two patients presented here were both symptomatic, with venography demonstrating subclavian vein occlusion. Both were approximately one year removed from device implant at the onset of symptoms, a common time frame for this occurrence. One had a single-lead pacemaker and the other a biventricular device. It may be that lead burden is only one of many contributing factors in this complication. Interestingly, both patients were on chronic therapeutic anticoagulation for the treatment of atrial fibrillation. The pathophysiology of lead-related venous stenosis may be unrelated to any acute thrombotic event but more likely is a chronic inflammatory and fibrotic reaction driven by endothelial injury and mechanical trauma. No prospective data exist on the benefit of anticoagulation therapy to prevent venous stenosis surrounding cardiac device implantation; this is an area in need of further study.

Both of our patients were treated with venoplasty and stenting due to unsatisfactory results with balloon inflation alone. The long-term outcomes of this approach are not known, and limited data exist for the use of this approach in the subclavian vein. It has been shown to be a reasonable strategy with good shortterm outcomes when used in the superior vena cava with retention of device leads. ${ }^{22}$ The dense fibrosis of these lesions, causing significant recoil, can lead to venoplasty failure. Aggressive balloon inflation in this setting may lead to perforation. Stenting is a safe alternative that improves procedural success and ipsilateral access. The obvious limitation of this technique is a lack of both short- and long-term data from a larger patient population specifically targeting subclavian vein stenosis. We have shown here that it is a safe and effective approach for the nearly immediate relief of symptoms in two patients. It is important to know it remains an option for the select group of patients with symptomatic subclavian vein stenosis related to an implanted cardiac device.

\section{Patient-Friendly Recap}

- Blockage of blood flow in the subclavian vein is common following placement of a cardiac device.

- This complication is occurring more frequently as the overall use of implanted devices increases.

- A combination of venoplasty and stenting may effectively relieve painful symptoms that afflict some patients.

\section{Acknowledgments}

The authors gratefully acknowledge Jennifer Pfaff and Susan Nord of Aurora Cardiovascular Services for editorial preparation of the manuscript, and Brian Schurrer and Brian Miller of Aurora Sinai Medical Center for assistance with figures.

\section{Conflicts of Interest}

None.

\section{REFERENCES}

1. Mond HG, Proclemer A. The 11th world survey of cardiac pacing and implantable cardioverter-defibrillators: calendar year 2009 - a World Society of Arrhythmia's project. Pacing Clin Electrophysiol. 2011;34:1013-27. CrossRef

2. Rozmus G, Daubert JP, Huang DT, Rosero S, Hall B, Francis C. Venous thrombosis and stenosis after implantation of pacemakers and defibrillators. J Interv Card Electrophysiol. 2005;13:9-19. CrossRef

3. Spittell PC, Hayes DL. Venous complications after insertion of a transvenous pacemaker. Mayo Clin Proc. 1992;67:25865. CrossRef

4. Stoney WS, Addlestone RB, Alford WC Jr, Burrus GR, Frist RA, Thomas CS Jr. The incidence of venous thrombosis following long-term transvenous pacing. Ann Thorac Surg. 1976;22:166-70. CrossRef

5. Antonelli D, Turgeman Y, Kaveh Z, Artoul S, Rosenfeld T. Short-term thrombosis after transvenous permanent pacemaker insertion. Pacing Clin Electrophysiol. 1989;12:280-2. CrossRef

6. Goto Y, Abe T, Sekine S, Sakurada T. Long-term thrombosis after transvenous permanent pacemaker implantation. Pacing Clin Electrophysiol. 1998;21:1192-5. CrossRef

7. Da Costa SS, Scalabrini Neto A, Costa R, Caldas JG, Martinelli Filho M. Incidence and risk factors of upper extremity deep vein lesions after permanent transvenous pacemaker implant: a 6-month follow-up prospective study. Pacing Clin Electrophysiol. 2002;25:1301-6. CrossRef 
8. Sticherling C, Chough SP, Baker RL, et al. Prevalence of central venous occlusion in patients with chronic defibrillator leads. Am Heart J. 2001;141:813-6. CrossRef

9. Robboy SJ, Harthorne JW, Leinbach RC, Sanders CA, Austen WG. Autopsy findings with permanent pervenous pacemakers. Circulation. 1969;39:495-501. CrossRef

10. Becker AE, Becker MJ, Claudon DG, Edwards JE. Surface thrombosis and fibrous encapsulation of intravenous pacemaker catheter electrode. Circulation. 1972;46:409-12. CrossRef

11. Wilkoff BL, Byrd CL, Love CJ, et al. Pacemaker lead extraction with the laser sheath: results of the pacing lead extraction with the excimer sheath (PLEXES) trial. J Am Coll Cardiol. 1999;33:1671-6. $\underline{\text { CrossRef }}$

12. Lickfett L, Bitzen A, Arepally A, et al. Incidence of venous obstruction following insertion of an implantable cardioverter defibrillator. A study of systematic contrast venography on patients presenting for their first elective ICD generator replacement. Europace. 2004;6:25-31. CrossRef

13. Haghjoo M, Nikoo MH, Fazelifar AF, Alizadeh A, Emkanjoo Z, Sadr-Ameli MA. Predictors of venous obstruction following pacemaker or implantable cardioverter-defibrillator implantation: a contrast venographic study on 100 patients admitted for generator change, lead revision, or device upgrade. Europace. 2007;9:328-32. CrossRef

14. Korzets A, Chagnac A, Ori Y, Katz M, Zevin D. Subclavian vein stenosis, permanent cardiac pacemakers and the haemodialysed patient. Nephron. 1991;58:103-5. CrossRef

15. Lin LJ, Lin JL, Tsai WC, Teng JK, Tsai LM, Chen JH. Venous access thrombosis detected by transcutaneous vascular ultrasound in patients with single-polyurethanelead permanent pacemaker. Pacing Clin Electrophysiol. 1998;21:396-400. CrossRef

16. Kim H, Chung JW, Park JH, et al. Role of CT venography in the diagnosis and treatment of benign thoracic central venous obstruction. Korean J Radiol. 2003;4:146-52. CrossRef

17. Sohal M, Williams S, Akhtar M, et al. Laser lead extraction to facilitate cardiac implantable electronic device upgrade and revision in the presence of central venous obstruction. Europace. 2014;16:81-7. CrossRef

18. Pace JN, Maquilan M, Hessen SE, Khoury PA, Wilson A, Kutalek SP. Extraction and replacement of permanent pacemaker leads through occluded vessels: use of extraction sheaths as conduits--balloon venoplasty as an adjunct. J Interv Card Electrophysiol. 1997;1:271-9. CrossRef

19. Kutarski A, Pietura R, Młynarczyk K, Małecka B, Głowniak A. Pacemaker lead extraction and recapture of venous access: technical problems arising from extensive venous obstruction. Cardiol J. 2012;19:513-7. CrossRef

20. Rogers DP, Lambiase PD, Chow AW. Successful coronary sinus lead replacement despite total venous occlusion using femoral pull through, two operator counter-traction and subclavian venoplasty. J Interv Card Electrophysiol. 2007;19:69-71. CrossRef

21. Moukabary T, Thai H, Thal S. Subclavian balloon venoplasty to facilitate lead implant in patient with subclavian venous obstruction. J Invasive Cardiol. 2011;23:E83-5.

22. Maluenda G, Bustos F, Viganego F, et al. Endovascular recanalization of central venous access to allow for pacemaker implantation or upgrade. Cardiovasc Revasc Med. 2012;13:215-8. CrossRef

23. Riley RF, Petersen SE, Ferguson JD, Bashir Y. Managing superior vena cava syndrome as a complication of pacemaker implantation: a pooled analysis of clinical practice. Pacing Clin Electrophysiol. 2010;33:420-5. CrossRef

24. Worley SJ, Gohn DC, Pulliam RW, Raifsnider MA, Ebersole BI, Tuzi J. Subclavian venoplasty by the implanting physicians in 373 patients over 11 years. Heart Rhythm. 2011;8:526-33. CrossRef

25. Spittell PC, Vlietstra RE, Hayes DL, Higano ST. Venous obstruction due to permanent transvenous pacemaker electrodes: treatment with percutaneous transluminal balloon venoplasty. Pacing Clin Electrophysiol. 1990;13:271-4. CrossRef

26. Garlitski AC, Swingle JD, Aizer A, Holmes DS, Bernstein NE, Chinitz LA. Percutaneous treatment of the superior vena cava syndrome via an excimer laser sheath in a patient with a single chamber atrial pacemaker. J Interv Card Electrophysiol. 2006;16:203-6. CrossRef

27. Park HW, Kim W, Cho JG, Kang JC. Multiple pacing leadinduced superior vena cava syndrome: successful treatment by balloon angioplasty. $J$ Cardiovasc Electrophysiol. 2005;16:221-3. CrossRef

28. Teo N, Sabharwal T, Rowland E, Curry P, Adam A. Treatment of superior vena cava obstruction secondary to pacemaker wires with balloon venoplasty and insertion of metallic stents. Eur Heart J. 2002;23:1465-70. CrossRef

29. Lindsay HS, Chennells PM, Perrins EJ. Successful treatment by balloon venoplasty and stent insertion of obstruction of the superior vena cava by an endocardial pacemaker lead. $\mathrm{Br}$ Heart J. 1994;71:363-5. CrossRef

30. Kirubakaran S, Behan MW, Mozid AM, Sabharwal T, Rinaldi CA. Percutaneous balloon venoplasty of pacemakerassociated superior vena cava obstruction to facilitate upgrade to a biventricular pacing system. Europace. 2011;13:1798800. CrossRef

31. Kalman PG, Lindsay TF, Clarke K, Sniderman KW, Vanderburgh L. Management of upper extremity central venous obstruction using interventional radiology. Ann Vasc Surg. 1998;12:202-6. CrossRef

32. Wilkoff BL, Love CJ, Byrd CL, et al. Transvenous lead extraction: Heart Rhythm Society expert consensus on facilities, training, indications, and patient management: this document was endorsed by the American Heart Association (AHA). Heart Rhythm. 2009;6:1085-104. CrosRef

33. Jacob S, Mohamad T. Pacemaker lead malfunction following superior vena cava stenting. Europace. 2009;11:1266. CrossRef

(C) 2015 Aurora Health Care, Inc. 